ISSN 0103-9954

\title{
ESTRUTURA DA REGENERAÇÃO NATURAL EM FLORESTA OMBRÓFILA MISTA NA FLORESTA NACIONAL DE SÃO FRANCISCO DE PAULA, RS ${ }^{1}$
}

\author{
STRUCTURE OF NATURAL REGENERATION IN MIXED RAINY FOREST AT THE SÃO \\ FRANCISCO DE PAULA NATIONAL FOREST, RS
}

Igor da Silva Narvaes ${ }^{2}$ Doádi Antônio Brena ${ }^{3}$ Solon Jonas Longhi ${ }^{4}$

\section{RESUMO}

O presente trabalho teve por objetivo caracterizar a regeneração natural, pela análise fitossociológica, em Floresta Ombrófila Mista na Floresta Nacional de São Francisco de Paula (entre $29^{\circ} 23^{\prime}$ e $29^{\circ} 27^{\prime}$ S e $50^{\circ} 23^{\prime}$ e $50^{\circ} 25^{\prime} \mathrm{W}$ ), para fornecer subsídios à recuperação e conservação desses ecossistemas, e descrever as possibilidades de utilização futura da regeneração natural. Foram amostradas 180 subunidades de $100 \mathrm{~m}^{2}$ $(10 \times 10 \mathrm{~m})$ nas quais foram medidas a altura total $(\mathrm{h})$ dos indivíduos com $\mathrm{h} \geq 1,30 \mathrm{~m}$, com circunferência mínima de 3,0 cm, até o máximo de $30,0 \mathrm{~cm}$. A densidade total foi de 7.984 indivíduos $/$ ha, pertencentes a 109 espécies, 88 gêneros e 46 famílias botânicas, além de indivíduos mortos, cipós e espécies não identificadas, com índice de diversidade de Shannon-Weaver (H') de 2,22. As espécies mais importantes foram Casearia decandra, Stillingia oppositifolia e Sebastiania brasiliensis. A Araucaria angustifolia apesar de ser a espécie fisionomicamente mais destacada e de maior interesse econômico da Floresta Ombrófila Mista apresentou valores baixos em todos os parâmetros avaliados, necessitando a implementação de tratamentos silviculturais e plantios de enriquecimento que beneficiem a sua regeneração.

Palavras-chave: regeneração natural; estrutura; Araucaria angustifolia; Floresta Ombrófila Mista.

\begin{abstract}
The aim of this paper was to characterize the natural regeneration through the analysis of the phytossociological structure, in a Mixed Rainy Forest at São Francisco de Paula National Forest (between $29^{\circ} 23^{\prime}$ and $29^{\circ} 27^{\prime} \mathrm{S}$ and $50^{\circ} 23^{\prime}$ and $50^{\circ} 25^{\prime} \mathrm{W}$ ), as a way of providing information regarding the recovery and conservation of these ecossistems, and describing the possibilities of future use of the natural regeneration. There have been sampled 180 subunits of $100 \mathrm{~m}^{2}(10 \times 10 \mathrm{~m})$ where there were measured the total heigth (h) of the individuals with $\mathrm{h} \geq 1,30 \mathrm{~m}$, with minimum circumference of $3,0 \mathrm{~cm}$, up to a maximum of $30,0 \mathrm{~cm}$. The total density was 7.984 individuals/ha, belonging to 109 species, 88 genera and 46 botanical families, besides dead individuals, lianas and no-identified species, with index of diversity of ShannonWeaver (H') of 2.22. The most important specie were Casearia decandra, Stillingia oppositifolia and Sebastiania brasiliensis. The Araucaria angustifolia in spite of being the outstanding physiognomic and the larger economical interest species of the Rain Forest, presented low values in all the evaluated parameters, needing forestation treatment and enrichment plantation that would specially benefit the development of its regeneration.
\end{abstract}

Key words: natural regeneration; structure; Araucaria angustifolia; Mixed Rainoit Forest.

\section{INTRODUÇÃO}

A Floresta Ombrófila Mista é tipo florestal de grande importância ecológico-econômica, por sua característica única de abrigar a conífera mais expressiva da vegetação brasileira - Araucaria angustifolia (Bertol.) Kuntze. A variedade de recursos naturais componentes desse tipo florestal é decorrente das

1. Parte da Dissertação intitulada Classificação e Caracterização da Regeneração Natural em Floresta Ombrófila Mista na Floresta Nacional de São Francisco de Paula, RS, apresentada no Programa de Pós-graduação em Engenharia Florestal.

2. Engenheiro Florestal, M.Sc., Assistente de Manejo Florestal da Celulose Irani S/A, Caixa Postal 87, CEP 89600000, Vargem Bonita (SC). igornarvaes@papel.irani.com.br

3. Engenheiro Florestal, Dr., Professor Adjunto e Pesquisador Aposentado do Departamento de Ciências Florestais, Centro de Ciências Rurais, Universidade Federal de Santa Maria, CEP 97105-900, Santa Maria (RS). dabrena@viars.net

4. Engenheiro Florestal, Dr., Professor Titular do Departamento de Ciências Florestais, Centro de Ciências Rurais, Universidade Federal de Santa Maria, CEP 97105-900, Santa Maria (RS). solon.longhi@pesquisador.cnpq.br

Recebido para publicação em 26/10/2004 e aceito em 27/10/2005. 
diferentes associações entre as espécies, as quais crescem influenciadas por variações ambientais intrínsecas (Gama et al., 2003 e Narvaes, 2004), sendo que as variações ocorrem em diferentes intensidades, de acordo com as características estruturais e seu estágio de regeneração natural. Estas influenciam na regeneração natural, bem como no estoque da floresta, sob diferentes intensidades, sendo enumeradas e elucidadas por Inoue (1979) como disponibilidade hídrica, intensidade luminosa, solo, competição, germinação e temperatura.

No passado, nesse tipo florestal, a degradação ocorreu especialmente, de acordo com Ladeira (2002), em virtude da qualidade de sua madeira e pela exploração desordenada, para suprir as fábricas de móveis e de celulose da Região Sul do Brasil e também para a exportação. Entretanto, apesar de ter sido muito explorado, ainda encontra-se ameaçado, sobretudo pela cultura da soja e, em alguns locais do estado pela criação de gado de forma extensiva, sendo que dos $25 \%$ de cobertura original do estado do Rio Grande do Sul (Carvalho, 1994), restam apenas 3,25\% (SEMA-RS/UFSM, 2001; 2002). Portanto, necessita ser preservado por meio da proteção integral de seus remanescentes e/ou pela execução de plano de manejo em regime sustentado, sobretudo pelo conhecimento da sua regeneração natural.

O termo regeneração natural apresenta uma amplitude de expressões e designações importantes para o entendimento do processo como um todo. Entretanto, com relação ao estoque da floresta, é conceituado por Rollet (1974) como as fases juvenis das espécies, por exemplo, em plantas com DAP inferior a $5 \mathrm{~cm}$, portanto referindo-se às fases iniciais de estabelecimento e crescimento das plantas, sendo que um ambiente favorável à maximização da produção qualitativa e quantitativa possibilitará a preservação, a conservação e a formação das florestas. Outros autores possuem diferentes critérios de inclusão de espécies como constituintes da regeneração, tais como Lamprecht (1990), o qual considerou como regeneração natural os indivíduos com altura igual ou superior a $30 \mathrm{~cm}$ e com DAP de até $10 \mathrm{~cm}$, sendo que tais critérios não servirão de parâmetro comparativo, pois a maioria dos estudos segue o seu próprio critério de inclusão.

A maioria dos remanescentes florestais poderiam encontrar-se em melhores condições, caso a exploração das espécies de interesse econômico tivesse levado em conta, sobretudo a regeneração natural, por meio do conhecimento de sua auto-ecologia, caracterização, estrutura e dinâmica, características essas fundamentais nas diretrizes dos planos de manejo, amplamente estudadas por diversos autores, como Roderjan (1983); Daniel e Jankauskis (1989); Guariguata e Pinard (1998); Amador e Viana (2000) e Eliasson et al. (2003). Atualmente, a legislação florestal brasileira (IBAMA, 2002) estabelece que a produção de informações a respeito do estoque da regeneração natural é imprescindível à elaboração de planos de manejo sob regime sustentado.

Carvalho (1980) elucida que, para estudar a regeneração natural e chegar à definição de parâmetros que viabilizem um manejo adequado, se deve considerar, entre outros aspectos, o estudo da estrutura da regeneração, o crescimento e os tratos silviculturais a serem aplicados na floresta, fornecendo dados que possibilitarão o monitoramento do desenvolvimento e comportamento futuro da floresta. De certa forma, o trabalho realizado por Araújo et al. (2001), na avaliação da estrutura diamétrica de bosques em regeneração corrobora a afirmação feita por Carvalho (1980), em que foram levadas em consideração as estruturas da regeneração, a distribuição diamétrica, a qualidade dos fustes bem como suas distribuições de volume e área basal, servindo de parâmetro relevante para a definição do manejo adequado da floresta.

O presente estudo teve como objetivo caracterizar a regeneração natural em Floresta Ombrófila Mista na Floresta Nacional de São Francisco de Paula de forma abrangente, como meio de fornecer subsídios a respeito da recuperação e conservação destes, pela análise da estrutura, com o intuito de descrever as possibilidades de utilização futura da regeneração natural.

\section{MATERIAL E MÉTODO}

\section{Área de estudo}

O estudo foi realizado na Floresta Nacional (FLONA) de São Francisco de Paula, localizada no Rincão dos Kröeff, no município de São Francisco de Paula, entre as coordenadas $29^{\circ} 23^{\prime}$ e $29^{\circ} 27^{\prime}$ S e 50 $23^{\circ}$ ' e $50^{\circ} 25^{\prime} \mathrm{W}$, no estado do Rio Grande do Sul. A área total de 1.606,69 hectares está situada na zona de transição entre Floresta Ombrófila Densa e Floresta Ombrófila Mista, dos quais 901,9 ha são de floresta 
nativa. O solo é do tipo Cambissolo Húmico Alumínico típico (Streck et al., 2002). Os valores médios anuais de temperatura e precipitação são, respectivamente, inferiores a $18,5^{\circ} \mathrm{C}$ e $2468 \mathrm{~mm}$ (Moreno, 1961).

\section{Amostragem e coleta dos dados}

Tomando-se como base as dez unidades amostrais demarcadas anteriormente, na floresta pelo Projeto PELD (Projeto Ecológico de Longa Duração) - Conservação e Manejo Sustentável de Ecossistemas Florestais, foram escolhidas seis unidades amostrais, adotando-se como critério de estratificação as características de declividade, a posição topográfica, as características físicas do solo e a exposição do terreno, sendo que em cada uma das dez faixas, que compõem as unidades amostrais de 1 ha, foram sorteadas três subunidades de $10 \times 10 \mathrm{~m}\left(100 \mathrm{~m}^{2}\right)$ por faixa, hachuradas em branco, totalizando trinta subunidades por hectare, conforme figura abaixo:

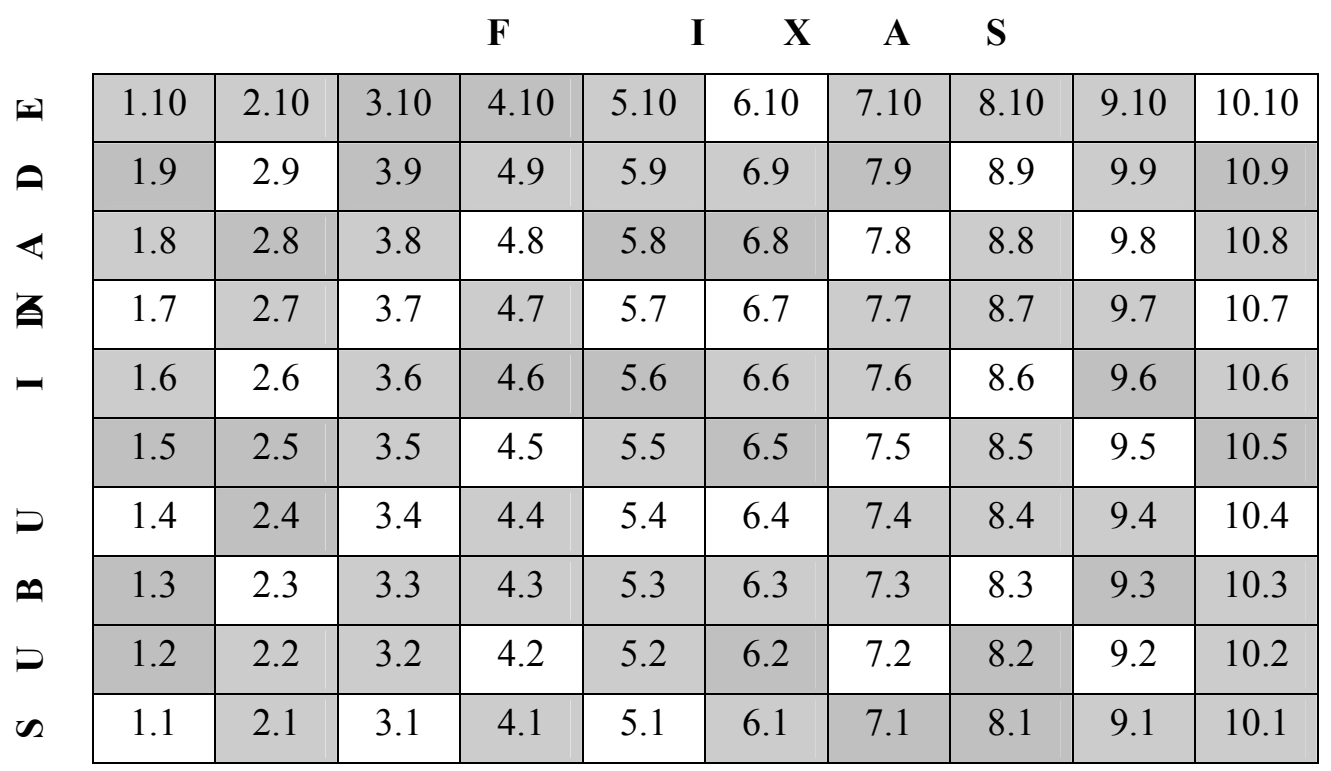

FIGURA 1: Desenho esquemático da unidade amostral de 1 ha $(100 \times 100 \mathrm{~m})$ e suas subunidades hachuradas em branco $(10 \times 10 \mathrm{~m})$ para o levantamento da regeneração natural na Floresta Ombrófila Mista na FLONA de São Francisco de Paula, RS, Brasil..

FIGURE 1: Scheme of the sample unit of 1 ha $(100 \times 100 \mathrm{~m})$ and its subunits in white grid $(10 \times 10 \mathrm{~m})$ used in the survey of the natural regeneration in the Mixed Rainy Forest at FLONA of São Francisco de Paula, RS, Brazil.

Nas subunidades, foram mensurados todos os indivíduos com altura superior a $1,30 \mathrm{~m}$ com circunferência à altura do peito (CAP) mínima de 3,0 cm, até a circunferência limite de $30,0 \mathrm{~cm}$, dos quais foram anotadas as seguintes informações: nome comum; altura total, circunferência a altura do peito; forma de vida: árvore, palmeira, arbusto, herbácea, trepadeira e cipó.

A identificação, em nível de família, gênero e espécie foi obtida por meio de consulta ao Herbário do Departamento de Ciências Florestais (HDCF), da Universidade Federal de Santa Maria, sob a supervisão do Professor Solon Jonas Longhi e, em caso de não-identificação, em um primeiro estágio, enviadas ao Botânico Marcos Sobral, da Universidade Federal de Minas Gerais.

\section{Análise dos dados}

A suficiência amostral foi obtida pela curva espécie-unidade, amplamente utilizada na análise de florestas nativas, dos mais variados tipos florestais (Narvaes, 2004).

Para a análise da estrutura horizontal da regeneração natural, os parâmetros considerados foram: densidade, freqüência, dominância, absolutas e relativas e valor de importância os quais estão descritos em Martins (1991).

No estudo da estrutura diamétrica, foram utilizadas as classes sugeridas e empregadas no Inventário 
Florestal Contínuo do Rio Grande do Sul (SEMA-RS/UFSM, 2001).

A diversidade florística da regeneração natural foi estimada pelo índice de Shannon-Weaver $\left(\mathrm{H}^{\prime}\right)$ $H^{\prime}=-\sum_{i=1}^{N}(p i \cdot \ln p i)$ calculado pelo logaritmo neperiano (Andrade et al., 2002), conforme segue abaixo:

Em que: $\mathrm{H}^{\prime}$ = índice de diversidade de Shannon-Weaver; $\mathrm{pi}=\mathrm{ni} / \mathrm{N} ; \mathrm{ni}$ = número de indivíduos da espécie i; $\mathrm{N}$ $=$ número total de indivíduos; $\ln =$ logaritmo neperiano.

\section{RESULTADOS E DISCUSSÃO}

\section{Composição Florística}

Foram amostrados 109 espécies, 88 gêneros e 46 famílias botânicas, além de indivíduos mortos cipós e espécies não-identificadas (Tabela 1). Com relação à riqueza florística, torna-se difícil encontrar parâmetros para a comparação na Floresta Ombrófila Mista, pois apesar de existirem estudos relevantes sobre a análise da regeneração natural (Vieira, 1987; Volpato, 1994; Jardim, 1995; Negrelle, 1995; Silva Mendes, 1998; Souza, 2000), estes foram realizados em outros tipos fitogeográficos. Entretanto, o estudo mais consistente para a comparação dos resultados foi realizado em toda região de ocorrência da floresta Ombrófila Mista, de forma sistemática, pelo Inventário Florestal Contínuo do Rio Grande do Sul (SEMARS/UFSM,2001).

Nesse trabalho, anteriormente citado, foram encontradas 202 espécies pertencentes a 56 famílias botânicas, além de indivíduos não-identificados, cipós, mortas e duas espécies exóticas.

TABELA 1: Espécies da regeneração natural amostradas em Floresta Ombrófila Mista na Floresta Nacional de São Francisco de Paula, RS. Densidade absoluta (DA), densidade relativa (DR), freqüência absoluta (FA), freqüência relativa (FR), dominância absoluta (DoA), dominância relativa (DoR), valor de importância (VI) e valor de importância percentual (VI).

TABLE 1: Specie of forest regeneration sampled in the Mixed Rainy Forest at São Francisco de Paula National Forest-RS. Absolute density (DA), relative density (DR), absolute dominance (DoA), relative dominance (DoR), importance value (VI) and percentage of importance value (VI\%).

\begin{tabular}{|c|c|c|c|c|c|c|c|c|c|}
\hline Nome Científico & Família & DA & DR & FA & FR & DoA & DoR & VI & $\mathrm{VI} \%$ \\
\hline Casearia decandra Jacq. & Flacourtiaceae & 1107,22 & 13,87 & 93,33 & 4,78 & 0,79584 & 16,4 & 35,05 & 11,68 \\
\hline $\begin{array}{l}\text { Stillingia oppositifolia Baill. ex } \\
\text { Müll. Arg. }\end{array}$ & Euphorbiaceae & 1456,11 & 18,24 & 57,22 & 2,93 & 0,47362 & 9,76 & 30,93 & 10,31 \\
\hline Sebastiania brasiliensis Spreng. & Euphorbiaceae & 851,67 & 10,67 & 61,67 & 3,16 & 0,75848 & 15,63 & 29,46 & 9,82 \\
\hline Morta & - & 258,89 & 3,24 & 85 & 4,36 & 0,23584 & 4,86 & 12,46 & 4,15 \\
\hline Outras (49 espécies)* & - & 157,20 & 1,95 & 130,56 & 6,71 & 0,15039 & 3,099 & 11,76 & 3,92 \\
\hline Rudgea parquioides (Cham.) Müll. Arg. & Rubiaceae & 489,44 & 6,13 & 58,33 & 2,99 & 0,10385 & 2,14 & 11,26 & 3,75 \\
\hline Matayba elaeagnoides Radlk. & Sapindaceae & 272,78 & 3,42 & 57,22 & 2,93 & 0,16402 & 3,38 & 9,73 & 3,24 \\
\hline Myrsine umbellata Mart. & Myrsinaceae & 204,44 & 2,56 & 60,56 & 3,1 & 0,13976 & 2,88 & 8,54 & 2,85 \\
\hline $\begin{array}{l}\text { Myrceugenia oxysepala (Burr } \\
\text { D. Legrand et Kausel }\end{array}$ & Myrtaceae & 244,44 & 3,06 & 57,78 & 2,96 & 0,07958 & 1,64 & 7,66 & 2,55 \\
\hline Calyptranthes concinna DC. & Myrtaceae & 192,22 & 2,41 & 55,56 & 2,85 & 0,10967 & 2,26 & 7,52 & 2,51 \\
\hline Myrceugenia cucullata D. Legrand & Myrtaceae & 207,22 & 2,6 & 53,33 & 2,73 & 0,10724 & 2,21 & 7,54 & 2,51 \\
\hline Myrcia oligantha O. Berg & Myrtaceae & 135,56 & 1,7 & 46,11 & 2,36 & 0,09463 & 1,95 & 6,01 & 2,00 \\
\hline Ilex paraguariensis A. St.-Hil. & Aquifoliaceae & 112,78 & 1,41 & 48,33 & 2,48 & 0,08929 & 1,84 & 5,73 & 1,91 \\
\hline $\begin{array}{l}\text { Myrceugenia myrcioides (Cambess.) } \\
\text { O. Berg }\end{array}$ & Myrtaceae & 133,89 & 1,68 & 43,89 & 2,25 & 0,07133 & 1,47 & 5,4 & 1,80 \\
\hline Campomanesia rhombea $\mathrm{O}$. Berg & Myrtaceae & 122,22 & 1,53 & 48,89 & 2,5 & 0,06503 & 1,34 & 5,37 & 1,79 \\
\hline
\end{tabular}


TABELA 1: Continuação ...

TABLE 1: Continued ...

\begin{tabular}{|c|c|c|c|c|c|c|c|c|c|}
\hline Nome Científico & Família & DA & DR & FA & FR & DoA & DoR & VI & $\mathrm{VI} \%$ \\
\hline $\begin{array}{llll}\text { lepharocalyx } & \text { salicifolius } & \text { (Kunth) } \mathrm{O} . \\
\text { erg }\end{array}$ & Myrtaceae & 96,11 & 1,2 & 44,44 & 2,28 & 0,08055 & 1,66 & 5,14 & 1,71 \\
\hline ryptocarya aschersoniana $\mathrm{Mez}$ & Lauraceae & 93,89 & 1,18 & 36,67 & 1,88 &, 06939 & 1,43 & 4,49 & 1,50 \\
\hline bess. & Sapil & 6,11 & 95 & &, 05 & 4659 & ,96 & 96 & 1,32 \\
\hline phoneugena reitzii D. Legrand & Myrtaceae & 58,89 & 0,74 & 34,44 & 1,76 & 0,06842 & 1,41 & 3,91 & 1,30 \\
\hline dia elegans Tul. & niaceae & 109,45 & 1,37 & 3,33 & 2,22 & 01262 &, 26 & 85 & 1,28 \\
\hline Imanonia ternata Vell. & Cunoniaceae & 84,44 & 1,06 & 28,89 & 1,48 & 0,06211 & 1,28 & 3,82 & 1,27 \\
\hline isel & & 66,11 & 0,83 & 3,33 & 1,71 & 06066 & 1,25 & 3,79 & 1,26 \\
\hline Schott) Mez & Lauraceae & 102,78 & 1,29 & 25 & 1,28 & 0,04756 & 0,98 & 3,55 & 1,18 \\
\hline pós & & & 0,77 & 35 & 1,79 & 0,04173 & 0,86 & 3,42 & 1,14 \\
\hline cotea pulchella Mart. & Laur & ,56 &, 82 & 29,44 & 1,51 &, 04513 & ,93 & 3,26 & 1,09 \\
\hline innamomum glaziovii (Mez) Kosterm. & Laur & 5,56 & 0,82 & 21,67 & 1,11 & 0,05823 & 1,2 & 3,13 & 1,04 \\
\hline & Sapindaceae & 115,56 & 1,45 & 13,89 & 0,71 & 0,04028 & 0,83 & 2,99 & 1,00 \\
\hline chltdl. & Annonaceae & 42,22 & 0,53 & 30,56 & 1,57 & 0,04125 & 0,85 & 2,95 & 0,98 \\
\hline rtifolia $(\mathrm{L}$ & Rosi & 47,22 & 0,59 & 30 & 1,54 & 0,03348 & 0,69 & 2,82 & 0,94 \\
\hline ess.) Baker & Aste & 57,22 & 2 & 26,67 & 1,37 & 397 & , & 2,79 & 93 \\
\hline$e x b r$ & Aqu & 41,67 & 0,52 & 26,6 & 1,37 & 125 & 0,85 & 2,74 & 0,91 \\
\hline issek & & 46,11 & 0,58 & 25 & & & & 2,63 & 0,88 \\
\hline & Myrtaceae & 32,22 & 0,4 & 25,56 & 1,31 & & 0,87 & 2,58 & 0,86 \\
\hline pseudosalzmannii Sleumer & Flacourtiaceae & 41,11 & 0,51 & 30 & 1,54 & 0,02378 & 0,49 & 2,54 & 0,85 \\
\hline B. Sm. et Downs & Euphorbiaceae & 42,78 & 0,54 & 23,89 & 1,22 & 0,03542 & 0,73 & 2,49 & 0,83 \\
\hline $\begin{array}{l}\text { lophylus edulis (A. St.-Hill et al } \\
\text { adlk }\end{array}$ & & 53,89 & 0,67 & 24,44 & 1,25 & 0,02620 & 0,54 & 2,46 & 0,82 \\
\hline anesia xanthocarpa O. Berg & Myrtaceae & 31,11 & & & 1,02 & & 0,57 & 1,98 & 0,66 \\
\hline olucrata DC. & Myr & 28,89 & 0,3 & & 0,91 & & 0,67 & 1,94 & 0,65 \\
\hline Lañuss. & Myrt & 30 & 0,3 & 19,4 & 1 & 0,02669 & 0,55 & 1,93 & 0,64 \\
\hline ica (Spreng & Lauraceae & 26,11 & 0,33 & 20 & 1,02 & 0,02620 & 0,54 & 1,89 & 0,63 \\
\hline tzsch & Prota & & 0,45 & 19,44 & 1 & & 0,3 & 1,8 & 0,60 \\
\hline anthe & Rutaceae & 38,33 & 0,48 & 15 & 0,77 & 0,02426 & 0,5 & 1,75 & 0,58 \\
\hline a angustifolia(Bertol.) Kuntze & & 22,78 & & 17,22 & 0,88 & & 0,55 & 1,72 & 0,57 \\
\hline of & Mryrtaceae & 25 & 0,31 & 15,56 & 0,8 & 0,02669 & 0,55 & 1,66 & 0,55 \\
\hline a uniflora (Pohl) D. Don & Solanaceae & 30,56 & 0,38 & 20,56 & 1,05 & 0,01019 & 0,21 & 1,64 & 0,55 \\
\hline rychnos brasiliensis (Spreng.) Mart. & Loge & 32,2 & 0,4 & 20 , & 1,05 & & 0,18 & 1,63 & 0,54 \\
\hline yrrninim atropurpureum scnou & Myrta & 26,67 & 0,3 & 21,11 & 1,08 & 0,00922 & 0,19 & 1,6 & 0,53 \\
\hline Dalbergia frutescens (Vell.) Britton & Fabaceae & 25 & 0,31 & 16,67 & 0,85 & 0,01601 & 0,33 & 1,49 & 0,50 \\
\hline onchocarpus nitidus (Vogel) Benth. & Fabaceae & 22,78 & 0,29 & 13,33 & 0,68 & 0,02232 & 0,46 & 1,43 & 0,48 \\
\hline Podocarpus lambertii Klotzsch ex Endl. & Podocarpaceae & 17,78 & 0,22 & 11,67 & 0,6 & 0,03009 & 0,62 & 1,44 & 0,48 \\
\hline ryptocarya moschata Nees & & 20,56 & 0,26 & 16,11 & 0,83 & 0,01068 & 0,22 & 1,31 & 0,44 \\
\hline & & & & & 0 , & & 0,36 & 1,31 & 0,44 \\
\hline Gordonia fruticosa (Schrad.) H. Keng & Theaceae & 33,89 & 0,43 & 10 & 0,51 & 0,01897 & 0,391 & 1,331 & 0,44 \\
\hline
\end{tabular}


TABELA 1: Continuação ...

TABLE 1: Continued ...

\begin{tabular}{|c|c|c|c|c|c|c|c|c|c|}
\hline Nome Científico & Família & $\mathrm{DA}$ & DR & FA & FR & DoA & DoR & VI & $\mathrm{VI} \%$ \\
\hline Luehea divaricata Mart. et Zucc. & Tiliaceae & 15,56 & 0,19 & 7,22 & 0,37 & 0,02475 & 0,51 & 1,07 & 0,36 \\
\hline Lippia ramboi Moldenke & Verbenaceae & 33,33 & 0,42 & 7,22 & 0,37 & 0,01310 & 0,27 & 1,06 & 0,35 \\
\hline Picramnia parvifolia Engl. & Simaroubaceae & 15,56 & 0,19 & 13,33 & 0,68 & 0,00534 & 0,11 & 0,98 & 0,33 \\
\hline Ilex dumosa Reissek & Aquifoliaceae & 12,22 & 0,15 & 8,33 & 0,43 & 0,01553 & 0,32 & 0,9 & 0,30 \\
\hline Seguieria aculeata L. & Phytolaccaceae & 22,22 & 0,28 & 9,44 & 0,48 & 0,00582 & 0,12 & 0,88 & 0,29 \\
\hline Myrciaria delicatula (DC.) O. Berg & Myrtaceae & 10,56 & 0,13 & 6,67 & 0,34 & 0,01407 & 0,29 & 0,76 & 0,25 \\
\hline Scutia buxifolia Reissek & Rhamnaceae & 10 & 0,13 & 7,22 & 0,37 & 0,01116 & 0,23 & 0,73 & 0,24 \\
\hline Duranta vestita Cham. & Verbenaceae & 12,78 & 0,16 & 7,78 & 0,4 & 0,00825 & 0,17 & 0,73 & 0,24 \\
\hline Ocotea diospyrifolia (Meisn.) Mez & Lauraceae & 16,11 & 0,2 & 5,56 & 0,28 & 0,00971 & 0,2 & 0,68 & 0,23 \\
\hline Solanum sanctae-catharinae Dunal & Solanaceae & 14,44 & 0,18 & 6,11 & 0,31 & 0,00679 & 0,14 & 0,63 & 0,21 \\
\hline Subtotal (60 sp.) & & 7826,69 & 98,05 & 1821,11 & 93,29 & 4,70231 & 96,90 & 288,2 & 96,08 \\
\hline Total & & $7.983,89$ & 100 & 1951,67 & 100 & 4,8527 & 100 & 300 & 100 \\
\hline
\end{tabular}

A riqueza florística é muito semelhante à encontrada no trabalho de Calegari (1999), efetuado na mesma floresta, contendo algumas parcelas similares ao presente estudo, entretanto realizada em menor intensidade amostral, no qual foram observadas cem espécies arbóreas e arbustivas, distribuídas em 68 gêneros e 37 famílias.

A família mais representativa na área do estudo foi Myrtaceae, com 21 espécies, seguida de Solanaceae (11 espécies), Lauraceae (dez espécies), Asteraceae, Euphorbiaceae, Flacourtiaceae e Rutaceae (cinco espécies). A ocorrência dessas famílias se mostrou coerente com os resultados encontrados em estudos nesse tipo florestal por Jarenkow (1985), Calegari (1999), SEMA-RS/UFSM (2001) e Mauhs \& Backes (2002). Analisando a família Myrtaceae, esta está sempre presente com elevada representatividade em diversos tipos florestais, conforme pode ser observado nos trabalhos que, de alguma forma, abordaram a regeneração natural, como os realizados por Jarenkow (1985), Calegari (1999), SEMA-RS/UFSM, (2001); Mauhs \& Backes (2002) e Araujo (2002).

A amostragem foi suficiente para a análise da composição florística da regeneração natural, pois, partindo dos $8100 \mathrm{~m}^{2}$, o ingresso de novas espécies (Figura 2) não ultrapassou $5 \%$ do total geral.

O índice de diversidade para a população estudada foi de 2,22. No estudo de SEMA-RS/UFSM (2001), na análise da regeneração natural e considerando os mesmos critérios de inclusão para todo o estado do Rio Grande do Sul, encontrou diversidade inferior ao presente estudo $\left(H^{\prime}=1,79\right)$, enquanto Mauhs \& Backes (2002) obtiveram um $H^{\prime}=2,90$ em um fragmento exposto a perturbações antrópicas, no mesmo tipo florestal para a regeneração natural.

Jarenkow (1985) verificou, na estação ecológica de Aracuri, no mesmo tipo florestal, índice de diversidade igual a 2,93, porém, no estrato considerado por ele como arbustivo (DAP $\geq 5,0 \mathrm{~cm}$ ). Foi possível verificar, com base nos resultados de diversidade citados que tais valores são influenciados pelo nível de inclusão do inventário e pelo histórico de uso da floresta.

Narvaes (2004), analisando os diferentes grupos ecológicos formados na regeneração natural da Floresta Ombrófila Mista, encontrou grande variação de diversidade entre os ambientes denominados como encosta inferior e encosta média e o grupo situado entre a encosta superior e platô, comprovando que as condições ambientais decorrentes de tais posições topográficas também possuem influência nos resultados da composição florística e, conseqüentemente, na diversidade. 


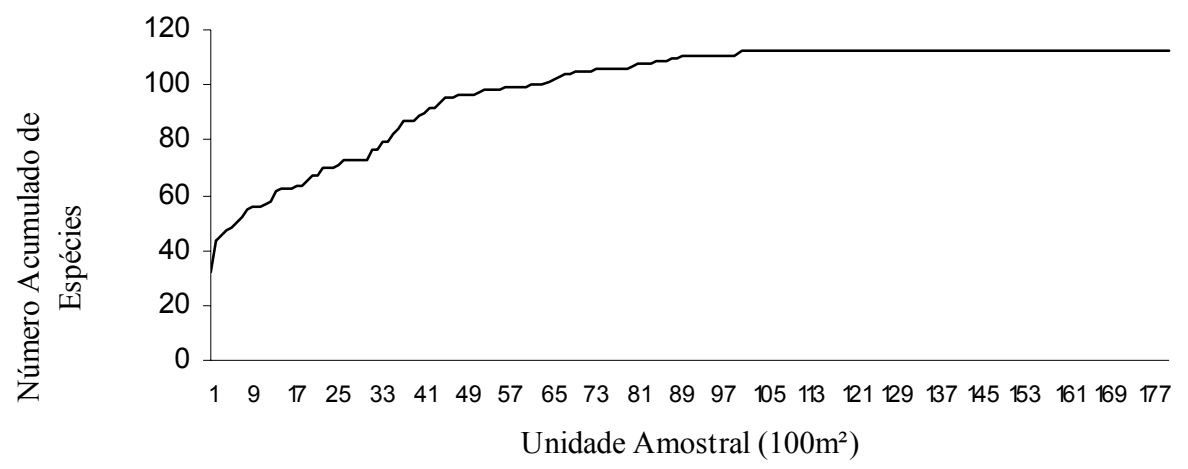

FIGURA 2: Curva espécie/área amostral da regeneração natural da Floresta Ombrófila Mista na FLONA de São Francisco de Paula, RS, Brasil.

FIGURE 2: Specie/sample area curve for the natural regeneration of a Mixed Rainy Forest at São Francisco de Paula National Forest-RS.

Cabe ressaltar que, do total de 109 espécies, as sessenta espécies componentes da Tabela 1 perfizeram mais de $96 \%$ do valor de importância da regeneração natural, demonstrando que estas realmente caracterizam a regeneração natural.

\section{Análise Estrutural}

O número médio de indivíduos na regeneração natural, considerando todos os indivíduos com CAP entre 3 e $30 \mathrm{~cm}$, resultou em 7.984 indivíduos/ha, com área basal de $4,8527 \mathrm{~m}^{2} / \mathrm{ha}$, sendo que tais valores são reflexo, sobretudo, das condições edafoclimáticas locais e do grau de conservação da floresta, influenciando diretamente na densidade da regeneração natural, ao se comparar o mesmo nível de inclusão dos indivíduos nas medições.

A altura total média da regeneração natural foi de $4,50 \mathrm{~m}$ e a máxima de $23,30 \mathrm{~m}$. Na análise dos parâmetros fitossociológicos da vegetação, observou-se o predomínio de Casearia decandra, Stillingia oppositifolia, Sebastiania brasiliensis, Rudgea parquioides, Matayba elaeagnoides, Myrsine umbellata, Myrceugenia cucullata, Calyptranthes concinna, Campomanesia rhombea e Blepharocalyx salicifolius, juntamente com os indivíduos mortos, perfazendo $54,31 \%$ do valor de importância da comunidade total analisada (Tabela 1).

A espécie melhor representada foi Casearia decandra, responsável por 11,68\% do valor de importância, apresentando os indivíduos de maiores dimensões diamétricas, representados pelo elevado valor de área basal $\left(0,7958 \mathrm{~m}^{2} / \mathrm{ha}\right)$, juntamente com Sebastiania brasiliensis $\left(0,7585 \mathrm{~m}^{2} / \mathrm{ha}\right)$. Todavia, a primeira se encontrou bem distribuída dentro das unidades amostrais, ao contrário da segunda, presente em somente $61,67 \%$ das unidades amostrais (Tabela 1 ).

Stillingia oppositifolia também se destacou, por apresentar o maior número de indivíduos por hectare, perfazendo 18,24\% do total analisado nas unidades amostrais da floresta. Essas três espécies citadas perfizeram 31,81\% do valor de importância total. Apesar de serem bastante representativas na regeneração, não possuem interesse econômico, apenas ecológico. Sebastiania brasiliensis e Stillingia oppositifolia são espécies adaptadas a ambientes úmidos, conforme descrito por Smith et al. (1988) e Backes \& Nardino (1998), respectivamente, enquanto que Casearia decandra é espécie generalista, adaptando-se a muitos habitats, sendo descrita por Marchiori (1997) como árvore pequena que habita, sobretudo o estrato médio da Floresta Ombrófila Mista, explicando sua alta densidade e freqüência, neste estudo.

A Araucaria angustifolia merece destaque, sobretudo pelo seu interesse econômico e por apresentar falhas na regeneração natural, como pode ser observado no estudo de Caldato et al. (1996). Sobre tal afirmativa, observou-se que Araucaria angustifolia, para a floresta analisada, apresentou valores baixos de densidade (22,78 ind/ha), freqüência (17,22\% das unidades amostrais) e dominância $\left(0,026 \mathrm{~m}^{2} / \mathrm{ha}\right)$, refletindo 
em uma baixa representatividade da espécie, ou seja, baixo valor de importância.

Ao se fazer um comparativo com os dados encontrados para a Araucária na regeneração natural da Floresta Ombrófila Mista do Estado (SEMA-RS/UFSM, 2001), observou-se que a densidade também possuiu valores pouco expressivos (22,5 ind/ ha).

A distribuição diamétrica da população amostrada apresentou forma de "J" invertido. Essa curva representa o equilíbrio dinâmico da floresta que se está auto-regenerando, considerando que a maior parte dos indivíduos se concentrou nas menores classes diamétricas, diminuindo progressivamente até atingir menor proporção nas maiores classes, evidenciando o padrão típico para florestas maduras, em estado de regeneração natural (Blanc et al., 2000) (Figura 3). Longhi (1980) observou que esse tipo de distribuição garante que o processo dinâmico da floresta se perpetue, pois a súbita ausência de indivíduos dominantes dará lugar para as chamadas "árvores de reposição".

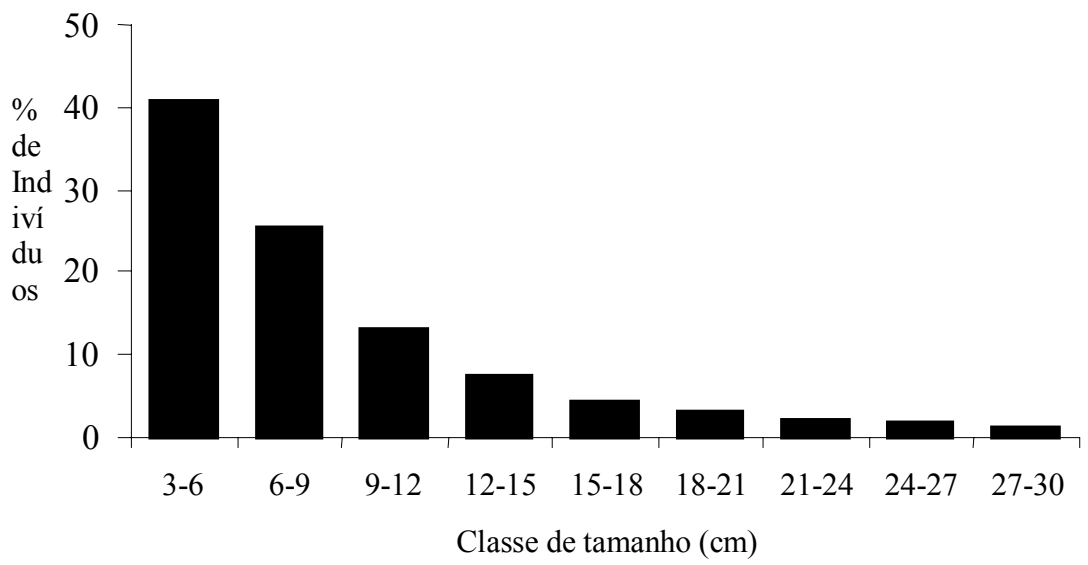

FIGURA 3: Distribuição percentual dos indivíduos em classes diamétricas, da Regeneração Natural da Floresta Ombrófila Mista na FLONA de São Francisco de Paula, RS, Brasil.

FIGURE 3: Percentage distribution of individuals by diameter classes for the natural regeneration of a Mixed Rainy Forest at São Francisco de Paula National Forest-RS.

Essa tendência parece ser a mais comum nos estudos realizados na avaliação da regeneração natural como pôde ser constatado no trabalho de Vieira (1987) em que a densidade absoluta diminuiu exponencialmente com o aumento das classes diamétricas, sob diferentes intensidades de redução de densidade $(0 \%, 25 \%, 50 \%$ e $75 \%)$ na floresta tropical úmida.

Analisando os aspectos florísticos da regeneração nas classes diamétricas, as espécies Luehea divaricata, Allophylus edulis, Eugenia involucrata e Ilex paraguariensis encontram-se bem representadas em todas as classes, sendo características desse estágio sucessional (Reitz et al., 1983; Carvalho, 1994; Longhi, 1995; Backes \& Irgang, 2002), e amplamente indicadas para plantios em áreas de regeneração com função de preservação permanente, como no caso de Eugenia involucrata.

É sempre oportuno salientar que esse tipo de floresta, mesmo nesse estágio, apresenta processo dinâmico expressivo, pois as mudanças de ambiente e sazonais em determinados locais causam alterações freqüentes, o que as mantêm com presença de muitas espécies pioneiras como Casearia decandra, Ocotea pulchella, Ocotea puberula, Sebastiania commersoniana, Matayba elaeagnoides e Myrsine umbellata, descritas por Reitz et al. (1983), Smith et al. (1988), Longhi (1995), Lorenzi (1998) e Backes \& Irgang (2002), e também por espécies que para as quais não foram encontradas literaturas sobre a sua autoecologia, mas que apresentaram caráter pioneiro, como Rudgea parquioides, que está somente presente nas menores classes de diâmetro. 


\section{Constituição da regeneração natural}

Analisando o hábito das espécies relacionadas na Figura 4, as árvores e arbustos representaram $95,03 \%$ da densidade relativa, os cipós $1,12 \%$, as herbáceas $0,52 \%$, os indivíduos mortos $3,24 \%$ e os nãoidentificados 0,076\%. Esses resultados diferem dos apresentados por Gama et al. (2003) que estudaram a regeneração natural de floresta de várzea, na Amazônia e verificaram que as árvores e palmeiras, essa última uma forma de vida comum neste tipo florestal representaram $36,1 \%$ da densidade relativa, os arbustos $21,4 \%$, as herbáceas $18,6 \%$, e os cipós $23,9 \%$. Tal discrepância nos resultados dá-se pelas características inerentes a cada tipo florestal, acarretados pelas diferenças de ambientais entre os tipos florestais.

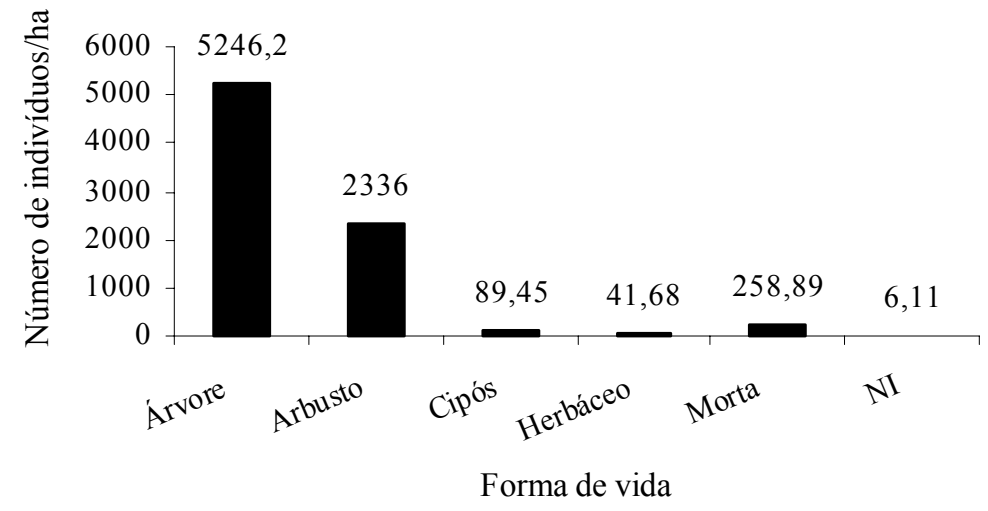

FIGURA 4: Densidade dos indivíduos, de acordo com sua forma de vida, registrados na regeneração natural inventariada da Floresta Ombrófila Mista na FLONA de São Francisco de Paula, RS, Brasil.

FIGURE 4: Density of individuals, in regard to the life form, found in the natural regeneration inventory of the Mixed Rainy Forest at São Francisco de Paula National Forest-RS.

Ao se comparar a freqüência de cipós com o estudo de SEMA-RS/UFSM (2001), ficou evidente que a sua presença se deu de forma menos efetiva, uma vez que, no Inventário Florestal Contínuo, foram encontradas cerca de $1,75 \%$ dessas espécies. Isso pode ser explicado pela afirmação de Hora \& Soares (2002), para os quais os cipós se desenvolvem bem em ambientes favoráveis à rápida taxa de crescimento, sendo encontrados mais freqüentemente em locais alterados (maior entrada de luz), decorrentes, sobretudo da formação de clareiras e no caso do estuário amazônico da inundação sazonal de sua floresta, favorecendo nesse último a ocorrência de cipós e ervas.

A baixa densidade de cipós é um dos fatores determinantes na avaliação do estágio de sucessão natural da floresta, sendo que a área desse estudo se encontra em estágio de sucessão natural mais próximo aos estágios mais avançados do que para o restante do tipo fitogeográfico o que, em parte, justifica a menor densidade de cipós. Entretanto, a incidência luminosa não deve ser desconsiderada, pois as espécies dessa forma de vida são notoriamente heliófilas.

Contudo, as árvores e os arbustos são notoriamente mais abundantes do que as demais formas de vida, sendo que essa dominância ocorre em razão da grande influência biótica exercida pelos indivíduos arbóreos, provavelmente por meio da chuva de sementes e também pelos indivíduos arbustivos em decorrência da dispersão zoocórica, pois grande parte dos arbustos neste trabalho, são da família Myrtaceae, os quais produzem frutos atrativos aos animais.

\section{CONCLUSÕES}

A análise dos resultados presentes neste estudo permitiu concluir que:

Os altos valores de importância de Casearia decandra, Stillingia oppositifolia e Sebastiania brasiliensis encontrados provaram que tais espécies são as mais características da regeneração natural na área estudada, sendo importantes para o processo de sucessão ecológica, criando condições para que as espécies 
de estágios sucessionais mais avançados se estabeleçam.

A baixa densidade de cipós indicou que não estão em estado de competição com os indivíduos arbóreos e arbustivos, não sendo necessário a realização de pré-corte, para a realização de futuras intervenções de manejo e explorações na área.

A Araucaria angustifolia apresentou baixa regeneração natural, caracterizado pelos valores inexpressivos dos parâmetros fitossociológicos, justificando a implementação de tratamentos silviculturais e plantios de enriquecimento que beneficiem o seu desenvolvimento, por se tratar da espécie de maior interesse comercial do tipo florestal.

\section{REFERÊNCIAS BIBLIOGRÁFICAS}

AMADOR, D. B.; VIANA, V.M. Dinâmica de "capoeiras baixas" na restauração de um fragmento florestal. Scientia Forestalis, Piracicaba, n. 57, p. 69-85, jun. 2000.

ANDRADE, L. A.; PEREIRA, I. M.; DORNELAS,G. V. Análise da vegetação arbóreo-arbustiva, espontânea, ocorrente em taludes íngremes no município de Areia - Estado da Paraíba. Revista Árvore, Viçosa, v. 26, n. 2, p. 165172, 2002.

ARAUJO, M. M. Vegetação e mecanismos de regeneração em fragmento de Floresta Estacional Decidual Ripária, Cachoeira do Sul, RS, Brasil. 2002. 153p. Tese (Doutorado em Engenharia Florestal) - Universidade Federal de Santa Maria, Santa Maria, 2002.

ARAUJO, P.A. et al. Estructura diamétrica de bosques en regeneración del chaco semiarido santiagueño. SIMPÓSIO BRASILEIRO DE PÓS-GRADUAÇÃO EM ENGENHARIA FLORESTAL, 2., 2001, Santa Maria. Anais... Santa Maria: UFSM, 2001. p. 211-230.

BACKES, P.; IRGANG, B. Árvores do sul: guia de identificação \& reconhecimento ecológico. Porto Alegre: Ed. Pallotti, 2002. 325p.

BACKES, A.; NARDINO, M. Árvores, arbustos e algumas lianas nativas no Rio Grande do Sul. São Leopoldo: Ed. UNISINOS, 1998. 202p.

BLANC, L.; MAURY-LECHON, G.; PASCAL, J. P. Structure, floristic composition and natural regeneration in the forests of Cat Tien National Park, Vietnam: an analysis of the successional trends. Journal of Biogeography, v. 27, p. 141-157, 2000.

CALDATO, S. L.; FLOSS, P. A; DA CROCE, D. M.; LONGHI, S. J. Estudo da regeneração natural, banco de sementes e chuva de sementes na reserva genética florestal de Caçador, SC. Ciência Florestal, Santa Maria, v. 6, n. 1, p. 27-38, 1996.

CALEGARI, J. Tamanho ótimo da unidade amostral para estudo da regeneração natural de uma Floresta Ombrófila Mista. Santa Maria: UFSM, 1999. 80p. Dissertação (Mestrado em Engenharia Florestal) -Universidade Federal de Santa Maria, Santa Maria, 1999.

CARVALHO, J.O.P. Inventário diagnóstico da regeneração natural da vegetação em área da Floresta Nacional de Tapajós. Belém: EMBRAPA-CPATU, 1980. 20p. (EMBRAPA-CPATU. Boletim de pesquisa, 2).

CARVALHO, P.E.R. Espécies florestais brasileiras: recomendações silviculturais, potencialidades e uso da madeira. Empresa Brasileira de Pesquisa Agropecuária, Centro Nacional de Pesquisas Florestais. Colombo: EMBRAPA-CNPF; Brasília: EMBRAPA-SPI, 1994. 640p.

DANIEL, O.; JANKAUSKIS, J. Avaliação de metodologia para o estudo do estoque de sementes do solo. Série IPEF, Piracicaba, v. 41-42, p. 18-26, 1989.

ELIASSON, L.; LAGESON, H.; VALINGER, E. Influence of sapling height and temperature on damage to advance regeneration. Forest Ecology and Management, Amsterdan, v. 175, p. 217-222, 2003.

GAMA J. R. V. et al. Estrutura e potencial futuro de utilização da regeneração natural de floresta de várzea alta no município de Afuá, Estado do Pará. Ciência Florestal, v. 13, n. 2, p. 71-83, 2003.

GUARIGUATA, M. R.; PINARD, M. A. Ecological knowledge of regeneration from seed in neotropical forest trees: Implications for natural forest management. Forest Ecology and Management. Amsterdan, v. 112, p. 87-99, 1998.

HORA, R. C.; SOARES, J. J. Estrutura fitossociológica da comunidade de lianas em um floresta estacional semidecidual na Fazenda Canchin, São Carlos, SP. Revista Brasileira de Botânica, São Paulo, v. 25, n. 3, p. 323-329, 2002. 
IBAMA - INSTITUTO BRASILEIRO DO MEIO AMBIENTE E DOS RECURSOS NATURAIS RENOVÁVEIS. Instrução Normativa n. 4 de 04/03/02. Brasília: IBAMA, 2002, 31p.

INOUE, M. T. Regeneração Natural: Seus problemas e perspectivas para as Florestas Brasileiras. Curitiba: FUPEF, 1979. 22p. (Série Técnica, 1).

JARDIM, F. C. S. Comportamento da regeneração natural de espécies arbóreas em diferentes intensidades de desbaste por anelamento, na região de Manaus - AM. 1995. 169p. Tese (Doutorado em Ciência Florestal) Universidade Federal de Viçosa, Vo osa 1995.

JARENKOW, J. A. Composição florística e estrutura da Mata com Araucária na Estação Ecológica de Aracuri, Esmeralda, Rio Grande do Sul. 1985. 86p. Dissertação (Mestrado em Ciências Biológicas) - Universidade Federal do Rio Grande do Sul, òrto Alegre, 1985.

LADEIRA, H. P. Quatro décadas de Engenharia Florestal no Brasil. Viçosa: Sociedade de Investigações Florestais, 2002. 207p.

LAMPRECHT, H. Silvicultura nos trópicos: ecossistemas florestais e respectivas espécies arbóreas - possibilidades e métodos de aproveitamento sustentado. Dt. Ges. Für Techn. Zusammenarbeit (GTZ), 1990.

LONGHI, R. A Livro das árvores: árvores e arvoretas do sul. Porto Alegre: Ed. L\&PM, 1995. 176p.

LONGHI, S. J. A estrutura de uma floresta natural de Araucaria angustifolia (Bert.) Ktze, no sul do Brasil. 1980. 198p. Dissertação (Mestrado em Ciência Florestal) - Setor de Ciências Agrárias - Universidade Federal do Paraná, Belém, 1980.

LORENZI, H. Árvores brasileiras: manual de identificação e cultivo de plantas arbóreas nativas do Brasil. Nova Odessa: Ed. Plantarum, 1998. 352p. v. 1.

MARCHIORI, J.N.C. Dendrologia das angiospermas: das magnoliáceas as flacurtiáceas. Santa Maria: Ed. da UFSM, 1997. 271p.

MARTINS, F.R. Estrutura de uma floresta mesófila. Campinas: UNICAMP, 1991. 246p.

MAUHS, J. ; BACKES, A. Estrutura fitossociológica e regeneração natural de um fragmento de Floresta Ombrófila Mista exposta a Perturbações Antrópicas. Botânica, n. 52, p. 89-109, 2002.

MORENO, J. A. Clima do Rio Grande do Sul. Porto Alegre: Secretaria da Agricultura, 1961. 42p.

NARVAES, I. S. Classificação e caracterização da regeneração natural em Floresta Ombrófila Mista na Floresta Nacional de São Francisco de Paula, RS. 2004. 143p. Dissertação (Mestrado em Manejo Florestal) - Universidade Federal de Santa Maria, Santa Maria, 2004.

NEGRELLE, R. R. B. "composição florística, estrutura fitossociológica e dinâmica de regeneração da floresta Atlântica na Reserva Volta Velha, Mun. Itapoã, SC".São Carlos: UFSC, 1995. 225p. Tese (Doutorado em Ecologia) - Universidade Federal de São Carlos, São Carlos, 1995.

RODERJAN, C. V. Morfologia do estágio juvenil de 24 espécies arbóreas de uma floresta de Araucária. 1983. 148p. Dissertação (Mestrado em Engenharia Florestal) - Universidade Federal do Paraná, Curitiba, 1983.

REITZ, R.; KLEIN, R. M.; REIS, A. Projeto Madeira do Rio Grande do Sul. Sellowia, Itajaí, n. 34-35, p. 1-525, 1983.

ROLLET, B. Lárchitecture de forêts denses humides sempervirens de Plaine. Norgent sur Marne: Centre Technique Forestier Tropical, 1974. 297p.

SEMA/UFSM-RS. Governo do Estado. Secretaria Estadual do Meio Ambiente. Relatório Final do Inventário Florestal Contínuo do Rio Grande do Sul. Porto Alegre, 2001. 706p. v.1, 2.

SEMA/UFSM-RS. Governo do Estado. Secretaria Estadual do Meio Ambiente. Inventário Florestal Contínuo do Rio Grande do Sul. Porto Alegre, 2002. 14p. (Fôlder).

SILVA MENDES, I. M. aplicação do método de amostragem de strand para estimação da densidade na regeneração natural de espécies arbóreas e arbustivas tropicais na amazônia ocidental. Curitiba: UFPR, 1998. 90p. Dissertação (Mestrado em Ciências Florestais) -Universidade Federal do Paraná, Curitiba, 1998.

SMITH, L. B.; DOWNS, R. J.; KLEIN, R. M. Euforbiáceas In: REITZ, P. R. (Ed.). Flora ilustrada Catarinense. Itajaí: Herbário Barbosa Rodrigues, 1988. 408p.

SOUZA, F. M. Estrutura e dinâmica do estrato arbóreo e da regeneração natural em áreas restauradas. 2000. 69p. Dissertação (Mestrado em Ciência Florestal) - Escola Superior de Agricultura "Luiz de Queiroz", Piracovaba,2000. 
STRECK, E. V. et al. Solos do Rio Grande do Sul. Porto Alegre: EMATER/RS, UFRGS, 2002. 107p.

VIEIRA, G. Análise estrutural da regeneração natural, após diferentes níveis de exploração em uma floresta tropical úmida. manaus: INPA, 1987. 164p. Dissertação (Mestrado em Ciências Biológicas) - Fundação Universidade do Amazonas, 1987.

VOLPATO, M. M. L. Regeneração natural em uma floresta secundária no domínio de Mata Atlântica: uma análise fitossociológica. Viçosa: UFV, 1994. 123p. Dissertação (Mestrado em Ciência Florestal) - Universidade Federal de Viçosa,Viçosa, 1994. 